\title{
Emerging Directions in Science, Publics, and Controversy
}

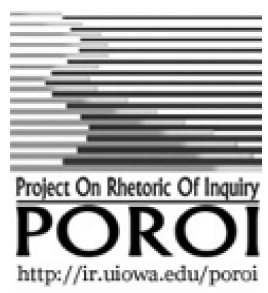

James Wynn

Department of English, Carnegie Mellon University

Pittsburgh, PA USA

Lynda Walsh

Department of English, University of Nevado, Reno

Reno, NVUSA

Poroi 9,1 (April 2013)

At the ARST Vicentennial Preconference, participants in the Octavian roundtable discussion on emerging directions in "Science, Publics, and Controversy" identified a number of important subjects that might guide the development of inquiry in the rhetoric of science, technology, engineering, and medicine/mathematics (STEMM). ${ }^{1}$ These subjects for research included the differing scales and types of scientific controversy, emerging techno-scientific issues, and the roles that rhetoricians might play in scientific controversies.

Scientific controversies develop between different groups for different reasons. Having a clear sense about the existing types of controversies is an important step in beginning to assess their dynamics. As participants in the discussion pointed out, controversies involving science might include intra- and inter-disciplinary disputes among scientists, conflicts between the lay public and scientists, and debates between political actors and scientists at local, state, national, and international levels. Currently, rhetoric and communication scholars and scholars in Science and Technology Studies have produced significant work that has assessed these types of controversies at the micro-level. Intra- and interdisciplinary disputes among scientists have garnered a great deal of attention, for example, from scholars interested in disciplinary boundary making (or unmaking) and scientific epistemology. In this category, we can locate such works as those of Ceccarelli (2001), Gieryn (1999), Prelli (1989), Wynn (2012), and, of course, Kuhn (1962). Controversies involving the lay public, science, and scientists over issues of public interest have also generated a considerable amount of research from STEMM scholars. These investigations were initiated by the work of sociologist Dorothy Nelkin (1979) and have increased exponentially in rhetoric and communication studies with the publication of works by Keränen (2010), Lynch (2011), Waddell (1996), and others. Of all of the

\footnotetext{
${ }^{1}$ Participants in the roundtable discussion included John Angus Campbell, Leah Ceccarelli, David Depew, Pia Vuolanto, Karen Taylor, Kenneth Walker, Lynda Walsh, and James Wynn.
} 
dimensions of conflict, the role of science in political debate seems to have garnered the least amount of representation in the rhetorical scholarship. In this area, the efforts of scholars in Science and Technology Studies such as Irwin (1995), Jasanoff (1990), and Wynne (1996) seem to have had the most impact. However, rhetoric and communication studies scholars such as Kinsella (2004) and Miller (2003) have also made important contributions.

That this list of scholars leaves out more than it includes suggests that scientific controversy has received a lot of attention. However, participants in the Octavian discussion believed that these controversies' argument types and dynamics still needed to be considered from a macrolevel perspective. In particular, a number of questions arose from the discussion, including "What are the similarities and differences in the ways that science is contested in these various settings?" and "How might understanding the differences in argument styles and strategies help rhetoric and communication scholars more effectively intervene in controversies?" These questions have already been taken up on a small scale in work on genre analysis (see, e.g., Swales, 1990) and accommodation (see, e.g., Fahnestock, 1986). However, a more comprehensive understanding of the various types and scales of controversy may illuminate features that have not, heretofore, been considered significant. As an example of the kind of scholarship needed in this area, one participant raised the idea of examining a topic in the global warming controversy from the local level up to the very broadest level of international scientific and political argument, comparing discourse at each of these levels.

In addition to comparing scientific controversies of different kinds and scales, participants discussed emerging techno-scientific issues that they believed were most likely to become important sources for scholarly investigation in the next five to ten years. Synthetic genetics was at the top of the agenda because of the recent breakthroughs in genetic modification and the creation of novel artificial organisms. The science of creating organisms has already begun to generate legal debates about patenting life as well as public sphere controversy over the possible risks of the introduction of man-made organisms into natural eco-systems. Because of its propensity to generate legal and social conflict, synthetic genetics was deemed a fertile site for the investigations of rhetoric and communication scholars.

Beyond biology, participants identified the development of digital technologies as a site for new research. Over the last five years, the technological affordances of the Internet have created new opportunities for scientists and lay specialists to engage with science and each other. In particular, the Internet and Internet-connectable devices have encouraged the emergence of a new kind of "citizen science" by enabling laypersons, either alone or in collaboration with scientists, to collect, organize, and communicate data. The level of collaboration and participation by citizens and scientists in these Internet-supported activities varies and can have different consequences for argument and communication. Contributive citizen science projects, like Galaxy Zoo or the online game FoldIt, for example, allow the least amount of input from 
laypersons. They solicit the skills or resources of the public to process growing mounds of scientific data or to solve tough problems when computers and scientists lack the resources or capabilities to undertake certain projects. Because these new digital collaborations require scientists to figure out how to work with the public to solve scientific problems, they serve as new areas for genre and accommodation studies research.

Besides contributive citizen science projects, there are also collaborative, co-created, and citizen-directed projects that offer opportunities to explore how the digital age is changing communication about science in both the public and technical spheres. In citizen-directed citizen science, for example, the Internet and Internet-associated devices have empowered laypersons to gather data about risk and to challenge institutional measurement practices that were previously difficult or impossible to scrutinize. Using new digital tools, groups such as Safecast and the Surface Stations project have begun to establish defensible critical lay-perspectives using techno-scientific evidence and argument. This opening of the technical sphere to lay publics represents a new frontier for exploration by rhetoric and communication scholars interested in the changing dynamics of argument between the public and the technical sphere.

In addition to influencing the study of argument, changes in technology might also provide fertile ground for developing new critical perspectives in rhetorical theory. One particularly radical way that technological changes are beginning to affect the rhetoric of public scientific controversy is by calling into question traditional notions of agency. Most modern rhetorical theory primarily addresses human agents. However, recent controversies involving climate models and fraudulent visualizations highlight the ways in which knowledge makingand as a consequence agency-is being shifted beyond human actors as computers and computerized processes assume an increasingly important role in the process. Without humans minding the store, so to speak, questions such as "What assumptions are coded into programs?" and "How do we check or certify the fidelity of computer-generated knowledge?" become of heightened concern. As these processes extend their reach into science, mathematics, and technology, rhetoricians of science may need to expand their critical notions of agency to embrace and assess these emergent features of controversy in the digital age.

The final major question raised at the Octavian session was "What role(s) should rhetoric and communication scholars adopt in their efforts to intervene in scientific controversies?" This question generated a number of positions that are worthy of future study and consideration. For some participants, the traditional role of the rhetorician/ communication specialist as agonist was most relevant. In an agonistic role, the main goal of rhetorical intervention is to generate public controversy on techno-scientific issues. While serving as the catalyst for public debate was central to some participants' notions of intervention, others thought that rhetoric and communication scholars should focus on adopting the role of counselor in moments of controversy. In this role, the goal of rhetoric and communication scholars would be to work with a 
particular side in an already existing public debate to help them understand the nature of the controversy and to diagnose problems of communication and argument. During the discussion, participants mentioned that some scientists were perhaps most in need of this kind of intervention because of their lack of experience with rhetoric and communication scholarship and because of concerns that publicallyrelevant issues like global warming could be negatively impacted by spurious tactics of argument.

Although the idea of the rhetoric/communication scholar as counselor was embraced by many participants, others expressed concern that adopting this perspective might encourage scholars to assume the role of public relations agent for one group or another. In order to maintain a more open, sophistic perspective on controversy, some participants argued that rhetoric and communication scholars should instead adopt the position of an "honest broker," to adopt a term from Roger Pielke Jr. (2007). As honest brokers, scholars would work for neither side but have as their goal the illumination of the strategies of discourse and argument used by both sides in the debate. Through this illumination, the rhetoric/communication scholars would encourage both sides to consider how their choices might be construed by their audiences and opponents and how such choices might advance or impede their collective goals for argument. The multitude of perspectives shared by roundtable suggests that the topic of intervention is one that requires further consideration and articulation. This is particularly important at this moment when STEMM scholars have begun to consider seriously how they might practically apply methods and concepts from the field to address realworld problems of communication and argument.

In conclusion, our Octavian discussion revealed that the area of science, publics, and controversy is a vibrant sub-field of STEMM rhetoric and communication research with a number of existing and emerging paths for scholarly engagement. It suggested that although important micro-level work has examined the different kinds of controversies and their dynamics, significant work remains to investigate these phenomena at different scales of engagement. In addition, emerging topics in science and technology, such as synthetic biology and Internet-enabled citizen science, provide fodder for new research in the study of genre, critical theory, and public argument. Finally, our conversation revealed a need for more detailed consideration of how rhetoric and communication scholars have-and might in the future-intervene in scientific controversy. By thinking critically about these roles, we can generate further interest in planning and participating in these interventions. The wealth of subjects waiting to be examined and the important contributions that STEMM rhetoric and communication scholars can make to the assessment and mitigation of scientific controversy suggests that investigations in the area of science, publics, and controversy provides fertile ground for rhetoric and communication studies to expand.

\section{References}

Ceccarelli, L. (2001). Shaping science with rhetoric: The cases of Dobzhansky, Schrodinger, and Wilson. Chicago, IL: University of 
Chicago Press.

Fahnestock, J. (1986). Accommodating science: The rhetorical life of scientific facts. Written Communication, 15(3), 330-50.

Gieryn, T. (1999). Cultural boundaries of science: Credibility on the line. Chicago, IL: University of Chicago Press.

Irwin, A. (1995). Citizen science: A study of people, expertise, and sustainable development. London, UK: Routledge.

Jasanoff, S. (1990). The fifth branch: Science advisors as policy makers. Cambridge, MA: Harvard University Press.

Keränen, L. (2010). Scientific characters: Rhetoric, politics, and trust in breast cancer research. Tuscaloosa, AL: University of Alabama Press.

Kuhn, T. (1962). The structure of scientific revolutions. Chicago, IL: University of Chicago Press.

Kinsella, W. (2004). Public expertise: A foundation for citizen participation in energy and environmental decisions. In S. Depoe, J. Delicath, \& M. Aepli Elsenbeer (Eds.), Communication and public participation in environmental decision making (pp. 83-95). New York: SUNY Press.

Lynch, J. (2011). What are stem cells? Definitions at the intersection of science and politics. Tuscaloosa, AL: University of Alabama Press.

Miller, C. (2003). The presumption of expertise: The role of ethos in risk analysis. Configurations, 11(2), 163-202.

Nelkin, D. (Ed.). (1979). Controversy. Beverly Hills, CA: Sage Publications.

Pielke, Jr., R. A., (2007). The honest broker: Making sense of science in policy and politics. Cambridge, UK: Cambridge University Press.

Prelli, L. (1989). A rhetoric of science: Inventing scientific discourse. Columbia, SC: University of South Carolina Press.

Swales, J. (1990). Genre analysis: English in academic and research settings. Cambridge, MA: Cambridge University Press.

Waddell, C. (1996). Saving the Great Lakes: Public participation in environmental policy. In C. Herndl \& S. Brown (Eds.), Green culture: Environmental rhetoric in contemporary America (pp. 141-165). Madison, WI: University of Wisconsin Press.

Wynn, J. (2012). Evolution by the numbers: The origins of mathematical argument in biology. Anderson, SC: Parlor Press.

Wynne, B. (1996). Misunderstood misunderstandings: Social identities and the public uptake of science. In A. Irwin \& B. Wynne (Eds.), Misunderstanding science?: The public reconstruction of science and technology (pp. 281-304). Cambridge, UK: Cambridge University Press. 